\title{
Clinical Radiography Education across Europe
}

A. England ${ }^{a, b^{*}}$, S. Geers-van Gemerena, ${ }^{c}$, A. Henner ${ }^{a, d}$, T. Kukkesa, ${ }^{e}$, D. Pronk-Larive ${ }^{a}$, L. Rainford $^{a, f}$, J.P. McNulty ${ }^{a, f}$

a European Federation of Radiographer Societies, Catharijnesingel 73, 3511 GM Utrecht, The Netherlands

b Directorate of Radiography, School of Health Sciences, University of Salford, Allerton Building, Salford M5 4WT, United Kingdom

c Nederlandse Vereniging Medische Beeldvorming en Radiotherapie, Catharijnesingel 73, 3511 GM Utrecht, The Netherlands

d School of Health and Social Care, Oulu University of Applied Sciences, Kiviharjuntie 8, FI90220 Oulu, Finland

e Tartu Health Care College, Nooruse 5, 50411, Tartu, Estonia

f Radiography and Diagnostic Imaging, School of Medicine, University College Dublin, Health Sciences Centre, Belfield, Dublin 4, Ireland

*Andrew England (corresponding author)

Email: A.England@salford.ac.uk

Telephone: +44 1612950703 
Abstract

Purpose: To establish a picture of clinical education models within radiography programmes across Europe by surveying higher education institutions registered as affiliate members of the European Federation of Radiography Societies (EFRS).

Method: An online survey was developed to ascertain data on: practical training, supervisory arrangements, placement logistics, quality assurance processes, and the assessment of clinical competencies. Responses were identifiable in terms of educational institution and country. All educational institutions who were affiliate members at the time of the study were invited to participate $(n=46)$. Descriptive and thematic analyses are reported.

Results: A response rate of $82.6 \%(n=38)$ was achieved from educational institutions representing 21 countries. Over half of responding institutions $(n=21)$ allocated in excess of 60 European Credit Transfer and Accumulation System (ECTS) credits to practical training. In nearly three-quarters of clinical placements there was a dedicated clinical practice supervisor in place; two-thirds of these were employed directly by the hospital. Clinical practice supervisors were typically state registered radiographers, who had a number of years of clinical experience and had received specific training for the role. Typical responsibilities included monitoring student progress, providing feedback and completing paperwork, this did however vary between respondents. In almost all institutions there were support systems in place for clinical placement supervisors within their roles.

Conclusions: Similarities exist in the provision of clinical radiography education across Europe. Clinical placements are a core component of radiography education and are supported by experienced clinical practice supervisors. Mechanisms are in place for the selection, training and support of clinical practice supervisors. Professional societies should work collaboratively to establish guidelines for effective clinical placements. 


\section{Highlights}

- First European survey of clinical radiography education.

- Practical component of radiography programmes deeply embedded.

- Clinical practice supervision fundamental.

- Variations between institutions exist. 


\section{Introduction}

Radiographic practice is over one hundred years old and from the outset the role of the radiographer has constantly changed and continues to evolve in parallel with advances in technology. Maintaining workforce capacity, whilst reacting to the latest clinical demands on radiographer training, is a key responsibility of radiography educators. Within Europe this is typically provided by universities, technical institutes and vocational colleges. A report by the European Federation of Radiographic Societies (EFRS) evaluated the landscape of radiography education across Europe. ${ }^{1}$ Founded in 2008, the EFRS currently represents over 100,000 radiographers and 8,000 student radiographers across Europe through 37 national societies and 57 educational institutions. The Educational Wing of the EFRS, established in 2010, is comprised of all of the educational institutions that are affiliate members of the EFRS and its aim is to promote and develop all levels of radiography education and research across Europe. The EFRS report ${ }^{1}$ focused on a broad spectrum of issues including the underpinning curricula, duration of study, credit load, accreditation requirements, staff qualifications, exchange opportunities and the availability of postgraduate programmes. One of the key outcomes from the report was that significant diversity exists between institutions, especially when spread across international borders. Despite the alignment efforts of the Higher Education Network of Radiographers in Europe (HENRE), a thematic network co-financed by the European Commission through the 'Tuning Educational Structures in Europe' project, $^{2-4}$ the EFRS Education report ${ }^{1}$ highlighted significant differences between radiography programmes across Europe. The university driven 'Tuning' projects aim was to offer a definitive approach to facilitate the implementation of Bologna (European process to ensure comparability in the standards and quality of higher-education qualifications), whilst also preserving autonomy and freedom of

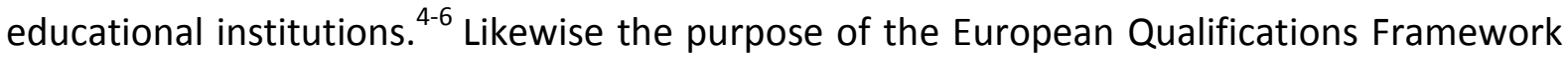
(EQF) is to aid Member States, educational institutions, employers and individuals in the comparison of qualifications across the European Union's diverse education and training systems. ${ }^{5,7-9}$ This led the EFRS to publish their EQF Level 6 Benchmarking Document: Radiographers. ${ }^{8}$

The process of educating a radiographer is multifaceted and typically incorporates a split between academic studies within a university or college and a practical component usually 
within a hospital or health centre. ${ }^{10}$ Given the results of the EFRS survey ${ }^{1}$ and the widespread differences in healthcare provision between EU Member States ${ }^{11}$ it is likely that there may be distinct differences in the provision of clinical radiography education. This has recently been brought to light with the publication of a report detailing the inclusion of patient safety within radiography curricula across Europe. ${ }^{12}$ It is, therefore, a core aim of the EFRS organisation to report the current status of clinical radiography education across Europe.

\section{Methods}

Design

The research design was an online survey using a questionnaire developed by the EFRS Educational Wing focusing on key issues relating to clinical radiography education. The questionnaire comprised of open and closed questions and consisted of sections designed to ascertain data on: amount and types of practical training within a programme (two questions), supervisory arrangements (ten questions), placement logistics (two questions), quality assurance processes (one question) and the assessment of clinical competencies (two questions). All respondents consented to data being identifiable in terms of educational institution and country. The Dutch Society of Radiographers was enlisted to help develop and deploy the online survey in conjunction with the Dutch research agency $\mathrm{MWM}^{2}\left(\mathrm{MWM}^{2}, \mathrm{Amsterdam}, \mathrm{ML}\right)$, backtracking was not permitted between sections of the survey.

\section{Participants}

All 46 educational institutions, that were EFRS affiliate members (educational institutions) at the time of the study, were invited to complete the survey between November 2014 and January 2015. An initial response deadline of two weeks was stated and two follow-up emails were sent to non-responding institutions.

\section{Data analysis}

All data were uploaded to SPSS Version 20 (IBM, Armonk, NY). Descriptive statistics are reported for most analyses while open questions were examined using thematic analysis. For the purposes of assessing the contribution of practical training to a programme the 
European Credit Transfer and Accumulation System (ECTS) was used. By way of an example a single year of full-time study typically generates 60 ECTS (in the United Kingdom credit system this would equate to 120 credits).

\section{Results}

Responses were received from 38 of the 46 educational institutions giving a response rate of $82.6 \%$ representing 21 countries. The educational institutions that participated in this survey are listed in Table 1 together with a three digit identifier. The three-digit identifier facilitates the identification of individual institutional responses for each question and has been used in similar publications. ${ }^{1,12}$

\section{Time available for practical training}

Respondents were asked to state the total amount of practical training for the students in both skills labs (educational institution based X-ray training facility or similar) and in the clinical practice setting during the whole period of education and training. Responses were received from all 38 respondents for this question (Figure 1). The majority of institutions ( $n=21 ; A T 2, C H 1, D K 1, E E 1, F I 1, F I 2, F I 3, F I 4, G B 1, G R 1$ IE1, IT1, MT1, NL1, NL2, NO1, NO2, NO3, NO4, PT1, PT2) offered in excess of 60 ECTS of practical training for students during their programmes. This was followed by 11 institutions (AT1, BE1, CZ1, FR1, GB2, GB3, HU1, NL3, PT3, SE2, SE3) that incorporated between 51-60 ECTS of practical training for students in the skills lab and in clinical practice during their programmes. For the 21 institutions with in excess of 60 ECTS, the mean ECTS for practical training in their programmes was 76.9 (SD = 11.3; range: 62 to 96 ECTS)(Figure 1).

\section{$\underline{\text { Time allocated for training in skills labs }}$}

Respondents were asked to quantify the total amount of practical training that the students perform in the skills lab during the whole period of training (Figure 2). $55 \%(n=21)$ of programmes provided 15 ECTS or less of practical training within the skills labs (AT1, AT2, BE1, CZ1, DK1, FI2, FI4, FR1, GB1, GB2, GB3, IE1, IT1, LV1, MT1, NO2, NO3, NO4, SE1, SE2, SL1). Programmes offering greater than 26 ECTS of practical training in the clinical skills lab were in Belgium, the Netherlands and Portugal (BE2, NL1, NL3, PT1, PT2, PT3). 


\section{Clinical supervision of students}

Respondents were asked to identify the percentage of the total amount of ECTS clinical training that students perform under supervision. The percentage of the total amount varied from 10 to $20 \%$ of the time ( $n=3 ; A T 2, B E 2, L V 1)$ to in excess of $50 \%$ of the time ( $n=10 ; \mathrm{CH} 1, \mathrm{DK} 1, \mathrm{FI} 1, \mathrm{FI} 2, \mathrm{GB1}, \mathrm{IT1}, \mathrm{MT1}, \mathrm{NL2}$, NO1, NO3). For the 10 institutions with an excess of $50 \%$ of the student clinical training performed under supervision, the mean percentage was $84.6 \%$ (SD = 18.7\%; range: 55 to $100 \%$ ).

The majority, 79\% $(n=30)$, of institutions indicated that between 1 and 3 students were supervised by an individual clinical staff member during clinical placement. $8 \%$ ( $n=3 ; H U 1$, LU1, PT1) indicated that supervision was for 4 to 6 students and $13 \%$ ( $n=5$; DK1, GR1, IT2, NL1, NO1) indicated that between 7 to 10 students were supervised in this way.

The majority, $71 \%(n=27)$ indicated that there was a dedicated clinical practice supervisor available at all of their clinical placement sites. Six institutions (FI4, GR1, HU1, IT1, IT2, NO2) responded stating that they had a dedicated clinical placement supervisor in more than $75 \%$ of the clinical placement sites. Two institutions (BE2, SE2) had clinical practice supervisors in between 50 and $75 \%$ of placement sites and a further two (AT2, BE1) had supervisors in less than $50 \%$ of clinical sites. Only one institution (MT1) indicated that they had 'No' dedicated clinical practice supervisor at any of their clinical sites.

When asked about the clinical practice supervisors, $68 \%(n=26)$ institutions indicated that the dedicated clinical practice supervisors were paid by the hospital and $16 \%$ ( $n=6$; BE1, $\mathrm{CH} 1, \mathrm{EE} 1, \mathrm{GR} 1, \mathrm{LU1}, \mathrm{PT} 3)$ indicated that the posts were paid by the educational institution. Those who responded 'Other' (16\%, n=6; CZ1, FI2, FI4, HU1, MT1, SE2) indicated that their clinical practice supervisors were a mix of those paid for by the hospital and those paid for by the educational institution ( $n=3 ; C Z 1, H U 1, S E 2)$, that the clinical practice supervisors were radiographers working in the clinical department rather than dedicated clinical supervisors ( $n=2 ; F|2, F| 4)$, or a combination of clinical practice supervisors paid for by the educational institution and academic staff members ( $n=1 ;$ MT1). 
Respondents were invited to indicate the responsibilities of their respective clinical practice supervisors. Table 2 highlights the range and frequency of responsibilities of the clinical practice supervisors. Respondents were also asked to provide details on the requirements for selection as a clinical practice supervisor. 68.4\% (n=26; AT1, AT2, BE1, CH1, CZ1, EE1, F1, FI2, FI3, FI4, FR1, GB1, GB3, GR1, HU1, IE1, IT1, IT2, LV1, NO1, NO2, NO3, NO4, PT1, SE1, SL1) of institutions indicated that State registration as a radiographer was a requirement to work as a clinical practice supervisor. 57.9\% ( $n=22$; AT2, BE1, CH1, DK1, EE1, GB1, GB2, GB3, GR1, HU1, IT1, IT2, IE1, NL1, NL2, NL3, PT1, PT3, SE1, SE2, SE3, SL1) indicated that at least two years' experience as a qualified radiographer was a requirement, and $44.7 \%$ ( $n=17$; AT2, CH1, CZ1, DK1, EE1, FI1, FI3, GB1, GB3, IE1, IT1, LU1, NL1, NL2, SE1, SE3) indicated that training on supervision was a requirement. Those who responded 'Other' $(26.3 \%, n=10)$ indicated that requirements included: must be a registered radiographer with at least two years' experience and training in supervision ( $n=1 ; M T 1)$, three years clinical experience ( $n=2$; GB1, PT2), the highest basic education grade as possible ( $n=2 ;$ IT1, IT2), have some teaching training $(n=1 ; C H 1)$, must be established in a clinical department and be able to discriminate good from bad practice ( $n=1 ; G B 1)$, must work in a large hospital $(n=1 ; G R 1)$, be committed to CPD ( $n=1 ; I T 2$ ), have the right to train and supervise ( $n=2 ; E E 1, L V 1)$, or must be nominated by the clinical department ( $n=1 ; B E 2)$.

Respondents were asked whether training for clinical practice supervisors was compulsory, 44.7\% ( $n=17$; AT2, CH1, GB1, FI1, FI2, FI3, FI4, IE1, IT2, LU1, NO2, NL1, NL2, NL3, SE1, SE2) stated 'Yes' that training was compulsory for all clinical practice supervisors (Figure 3). For those who have training $68.4 \%(n=26)$ respondents indicated that teaching staff from the educational institution provided the training, $10.5 \%$ ( $n=4 ; A T 1, F I 3, N O 2, S E 2)$ indicated that the training was provided by clinical staff, while $21.1 \%$ ( $n=8$; AT2, HU1, LV1, NL2, PT1, PT2, SE1, SE3) indicated 'Other'. Those who responded 'Other' indicated that no such training is available ( $n=3$; HU1, LV1, PT2), academic courses are provided ( $n=3 ;$ AT2, SE1, SE3), and trainees can attend any external clinical practice supervision course $(n=1 ; N L 2)$.

The majority of institutions, 58\% ( $n=22$; AT1, BE1, BE2, CZ1, FI1, FI2, FI4, GB3, GR1, HU1, IT1, LV1, MT1, NO1, NO4, NL3, PT1, PT2, PT3, SL1), indicated that less than 10 hours of 
compulsory clinical practice supervision training was required. This was followed by $21 \%$ ( $n=8 ; A T 2, C H 1, D K 1, E E 1, G B 2, N O 3, S E 1, S E 3)$ who indicated that over 50 hours of training was required. For the eight institutions with in excess of 50 hours of training required for clinical practice supervisors the mean was 152 hours (SD = 72.9; range: 60 to 240 hours). Full details of the quantity of compulsory supervisory hours are illustrated in Figure 3.

As can be seen in Figure 4 a range of topics are commonly included in clinical supervisory training programmes.

Institutions were asked whether there are formal agreements with all participating clinical placement sites. The majority of institutions, $90 \%(n=34)$, indicated 'Yes' there was a formal agreement in place with all participating clinical sites, those without included GB2, GR1, MT1, NL2, SE3. Half of the institutions ( $n=19$; CH1, CZ1, DK1, EE1, FI1, FI2, FI3, FI4, GB1, HUI1, IT1, IT2, LV1, NO4, PT3, SE1, SE2, SE3, SL1) indicated that there was a financial payment made to the clinical sites.

\section{Quality assurance of clinical educational experience}

Thirty-two percent ( $n=12$; BE1, DK1, GB1, IE1, IT2, MT1, NL1, NL2, NL3, NO2, NO3, SE3) institutions indicated that regular audits of the clinical placement sites were performed. When asked to specify the frequency of these audits, seven institutions responded as shown in Figure 5. Most institutions used student questionnaires about the clinical placements $(86.8 \% ; n=33)$ or student questionnaires about the supervision by clinical staff $(68.4 \%$; $n=26)$.

The most commonly available support for the clinical practice supervisors in descending order of frequency were: 'meetings at the educational institution' (81.6\%), 'regular visits by academic staff' (76.3\%), 'training courses' (36.8\%) and 'web-based support' (42.1\%) (Figure 6). Those who responded 'Other' indicated: 'regular contact with academic staff', 'telephone contact, peer support network across sites', 'occasional consultations', and 'topic discussions'. 
The most commonly used methods for the assessment of clinical placement competences in descending order of frequency were: 'observation of professional practice' (76.3\%), 'written report' (73.7\%), 'portfolio' (57.9\%), 'reflective records' (55.3\%), 'case study' (50\%), 'oral presentation' (47.4\%), 'oral examination' (44.7\%), 'recording and reporting' (39.5\%) and 'OSCEs' (39.5\%). Respondents were asked to identify the individuals involved in the clinical assessment process be this formative assessment or summative assessment. The results are illustrated in Figure 7.

Respondents were finally asked whether they had reviewed the competences of their graduates to the EFRS European Qualifications Framework Level 6 Benchmarking document for Radiographers. ${ }^{8}$ Seventy-nine percent $(n=30)$ of respondents indicated 'Yes' they had reviewed the graduate competencies as outlined in the EFRS EQF benchmark document for level 6.

\section{Discussion}

As with previous reports there are identifiable differences in the provision of radiography education across Europe. ${ }^{1,12}$ Unsurprisingly, this survey has also revealed a number of differences in the delivery of the clinical side of radiography education. It is important to note that this survey included submissions from 38 institutions across 21 countries. From the data presented it is also clear that there are a number of commonalities between education providers. This discussion will focus around the similarities, differences and also provide future recommendations as to how clinical radiography education may evolve.

The amount of programme time allocated for practical training was similar between the participating institutions with the majority $(n=35)$ allocating more than 40 ECTS (Figure 1). This is likely to reflect the vocational nature of radiography and the need to provide competent practitioners upon qualification. It was perhaps surprising that a single institution indicated that they allocated only 10 to 20 ECTS for practical training. There could be several reasons for this; 1) post-qualification requirements for this institution/country are markedly different to the other institutions participating in this survey; 2) a significant proportion of practical training is completed following qualification, possibly as part of a preceptorship/internship process or pre-registration period. Interest is 
growing in this area, Nisbet (2008) reported on a model for preceptorship for newly qualified radiotherapy radiographers. ${ }^{13}$ In this work, it was identified that changes in educational strategies may have impacted on clinical competence and that it was essential to evaluate the potential effectiveness of a preceptorship programme.

The use of skills labs to teach the practical components of radiography was a key feature of many programmes. Despite this, the proportion of time in the skills labs as a direct component of the overall radiography programme was less than 16 ECTS for the majority of respondents $(n=21)$. This is likely to reflect the availability and facilities within skills labs and also the time commitment needed to provide equitable access for all students. It is widely accepted that skills labs provide a safe opportunity in which to learn, however, this cannot be a substitute for direct clinical experience with patients. Cosson and Willis (2012) identified the need for educational institutions of providing a means for providing highfidelity simulations of the clinical environment. ${ }^{14}$ More recently, we have seen extension of physical skill labs into virtual environments for providing radiography and radiotherapy education. $^{15}$

The supervision of students is an essential part of training and is fundamental for patient safety. Responses from the survey indicate that clinical practice supervision is well established across the majority of educational providers and countries. Variation was also identified in terms of supervisor / student ratios. This may be explained by possible differences in the roles of supervisors between institutions and countries. In some countries clinical practice supervisors are responsible for teaching, assessment and placement rotas. $^{16}$ In other situations a clinical practice supervisor will provide direct supervision of the student alongside performing day-to-day clinical radiographic examinations. Such variations may result from differences in the function of the clinical training site and its location relative to the educational provider. For several of the respondents the educational provider was based on the same site as the clinical placements; thus it is possible that their role could be different when compared to a hospital which is more remote. 
For the majority of respondents $(n=26)$ clinical practice supervisors were employed by the clinical placement i.e. hospital and not the university or educational provider. There were, however, a number of educational providers which directly employed the clinical practice supervisors $(n=6)$ to work alongside students when on clinical placement. For the remaining educational providers the employer was a partnership between clinical and academia. Such differences are likely to reflect differences in healthcare funding structures which exist across Europe and the final destination of students upon qualification.

The requirements for undertaking clinical practice supervision varied between responding institutions. From the results of this survey a number of similarities were identified. Most respondents indicated that clinical practice supervisors must be professionally registered, have a number of years of post-qualification experience i.e. at least two years, and have received training in clinical practice supervision. It was clear that all responding institutions placed value on the clinical practice supervision role and that this was an integral part of radiography training.

Common requirements for clinical practice supervisors were: to teach students $(50 \%)$, monitor the progress of students (87\%), provide feedback to students (95\%) and education providers (84\%), and to complete placement related paperwork (68\%). Several of the less common roles included working with educational providers to develop curricula. From the responses as a whole it appears that the role of the clinical practice supervisor is in the organisation of radiography education within the clinical environment and monitoring the assessment of clinical competencies.

The majority of respondents indicated that clinical practice supervisors are commonly required to undertake a small number of compulsory training hours. By way of example, for 25 respondents less than 21 hours of compulsory training were required. Respondents agreed that the main component of relevant courses included training on roles and responsibilities, monitoring student progress, and assessment. Rose and Best ${ }^{17}$ discussed the training requirements of clinical practice supervisors across a number of international health sciences programmes, they reported similar themes in that high standards are required from those who provide clinical healthcare education and this in turn requires 
support and infrastructure. Further guidance could be provided on the specific topics including in training courses and also time commitments necessary.

Over $90 \%$ of respondents indicated that there was a formal agreement between educational providers and clinical placement sites. Half of the respondents indicated that there was a financial arrangement between the educational provider and the clinical placement site. This is likely to reflect higher education funding differences across jurisdictions which influence the funding models for clinical training. In many instances the provision of clinical placements for students is reciprocal in order to help produce a steady supply of qualified radiographers in order to meet service demands. In many countries not all sites providing diagnostic radiography, nuclear medicine and radiotherapy will support the training of students. This is often a major challenge for educational providers and with the growing demand to train radiographers more innovative methods are required to extending the provision of student placements. As an example, Wareing and Henderson, in 2015, reported on the perceptions' of final year diagnostic radiography students when on an industrial radiography placement. ${ }^{18}$

Participants were invited to indicate what mechanisms were in place for the quality assurance of clinical placements. Approximately a third of institutions carry out regular audits and the main method of receiving feedback on clinical placements is via student questionnaires on placement sites (87\%) or on the supervision by staff members $(68 \%)$. Price et al. ${ }^{19}$ stated, in a UK based study, that the audit of clinical placements can be an effective tool in radiography education. The quality assurance of clinical placements may also be a requirement of relevant professional bodies and as part of the programme accreditation. This latter point was not evaluated in the questionnaire and could be a subject for future surveys.

The most common support mechanisms available for clinical practice supervisors were 'meetings at the educational institution' (81.6\%) and 'regular visits by academic staff' (76.3\%). A wide spectrum of training opportunities for clinical practice supervisors is desirable in order to reflect changing needs of the student. In many instances clinical practice supervisors will provide pastoral support to students and implement support plans 
for those identified as having special education needs such as dyslexia, other disabilities, and indeed personal or social difficulties.

Radiography education is constantly evolving with non-traditional courses being developed and accredited and existing courses undergoing regular review and change. This study provides a valuable picture of clinical education across Europe but only presents data from a single snapshot in time. Further limitations are that our study did not seek to capture the differences between clinical placement sites in terms of capacity, case mix and the rotation of students. It is likely that large differences could exist in the number of students at a placement, rotational practices used by education providers, differences in the availability of imaging equipment and the case mix for a site i.e. dedicated trauma centre versus dedicated cancer centre, or small private imaging centre versus large academic medical centre.

The issue of validation could be raised when considering our results. Data collection relied on a single person completing an online questionnaire for each affiliate member (educational institution). The correctness of individual responses would have some dependency on the respondents understanding of the English language and their knowledge of their own institution's practices. We accept that there are mechanisms which could have been used to test the validity of the collected data. Our decision not to undertake these additional activities was largely based on the time available to complete this study. We would argue that by engaging with the EFRS, and representing their institution, the respondents have indicated that they were conversant with the English language and that they were in a suitable position to have good understanding of their respective curricula.

A comparison of study findings against those published in the literature was difficult. Within radiography education, there is generally a lack of publications regarding clinical training. It is, therefore, important that methods are developed and research is encouraged to further develop the evidence based in this area.

\section{Conclusions and recommendations}


A large number of similarities exist in the provision of clinical radiography education across Europe. Clinical placements are core components of radiography programmes and the support from clinical practice supervisors is paramount. Mechanisms are largely in place for the selection, training and support of clinical placement supervisors and in many instances these are fundamental to the success of clinical education. Diversity exists across Europe and multi-national organisations such as the EFRS should consider methods to further harmonise the provision of clinical education. New radiography educators are being introduced in order to respond to the growing demand for radiographers and these institutions will require support when planning and delivering new programmes. To raise and maintain standards of clinical education, national and international organisations, such as the EFRS, have a role to play in formulating guidance on effective clinical placements including training on clinical supervision and quality assurance processes. 


\section{References}

1. McNulty, JP., Rainford, L., Bezzina, P., Henner, A., Kukkes, T., Pronk-Larive, D., Vandulek, C. A picture of radiography education across Europe. Radiography, 2016;22(1):5-11.

2. Challen V. Radiography in Europe: the HENRE perspective. Radiography 2006; 12:183-5.

3. European Commission. Tuning educational structures in Europe. Universities' contribution to the Bologna Process: an introduction. $2^{\text {nd }}$ Ed. Bilbao, Spain: European Commission Tuning Project; 2008. Available from http://www.unideusto.org/tuningeu/publications/generalbrochure.html [accessed 19.05.15].

4. Higher Education Network for Radiography in Europe. Final report of HENRE II 2005-2008. Cumbria, UK, HENRE Thematic Network; 2008. Available from: http://tuningacademy.org/wp-content/uploads/2014/02/HENRE-final-report-2005-2008.pdf

5. Castillo J, Caruana CJ, Wainwright D. The changing concept of competence and categorisation of learning outcomes in Europe: Implications for the design of higher education radiography curricula at the European level. Radiography 2011; 17:230-4.

6. Akimoto A, Caruana CJ, Shimosegawa M. A qualitative comparative survey of first cycle radiography programmes in Europe and Japan. Radiography 2009; 15:333-40.

7. European Parliament Council. Recommendation of the European Parliament and of the Council on the establishment of the European qualifications framework for lifelong learning. Official Journal of the European Union 2008; C111/1.

8. European Federation of Radiographer Societies. European Qualifications Framework (EQF) Level 6 Benchmarking Document: Radiographers. Utrecht, the Netherlands: European Federation of Radiographer Societies; 2014. Available from: http://www.efrs.eu/uploads/files/550d4d65-9c48-4841-83c0-

1b2450ace4bd.eqf\%20benchmarking\%20document\%20-\%20radiographers web.pdf

9. European Centre for the Development of Vocational Training. European guidelines for validating non-formal and informal learning. Luxembourg: Office for Official Publications of the European Communities; 2009.

10. Naylor, S., Ferris, C., Burton, M. Exploring the transition from student to practitioner in diagnostic radiography. Radiography 2016; 22(2):131-136.

11. Aiken, LH., Sermeus, W., Van den Heede, Koen., Sloane, DM., Busse, R., McKee, M et al. Patient safety, satisfaction, and quality of hospital care: cross sectional surveys of nurses and patients in 12 countries in Europe and the United States. BMJ 2012; 344:e1717.

12. England A, Azevedo KB, Bezzina P, Henner A, McNulty, J.P. Patient safety in undergraduate radiography curricula: A European Perspective. Radiography 2016; 22(1):S12-S19. 
13. Nisbet $\mathrm{H}$. A model for preceptorship - The rationale for a formal, structured programme developed for newly qualified radiotherapy radiographers. Radiography 2008;14(1):52-56.

14. Cosson P, Willis N. Digital teaching library (DTL) development for radiography education. Radiography 2012;18(2):112-116.

15. Shanahan M. Student perspective on using a virtual radiography simulation. Radiography 2016;22(3):217-222.

16. Fowler P, Wilford B. Formative feedback in the clinical practice setting: What are the perceptions of student radiographers? Radiography 2016;22(1):e16-e24.

17. Rose $M$, Best $D$. Transforming practice through clinical education, professional supervision and mentoring. 2005, Elsevier, London.

18. Wareing AK., Henderson I. Contemporary practice education: Exploring student perceptions of an industrial radiography placement for final year diagnostic radiography students. Radiography 2015;21(2):176-180.

19. Price R, Hopwood N, Pearce V. Auditing the clinical placement experience. Radiography 2000; 6(3):151-60. 


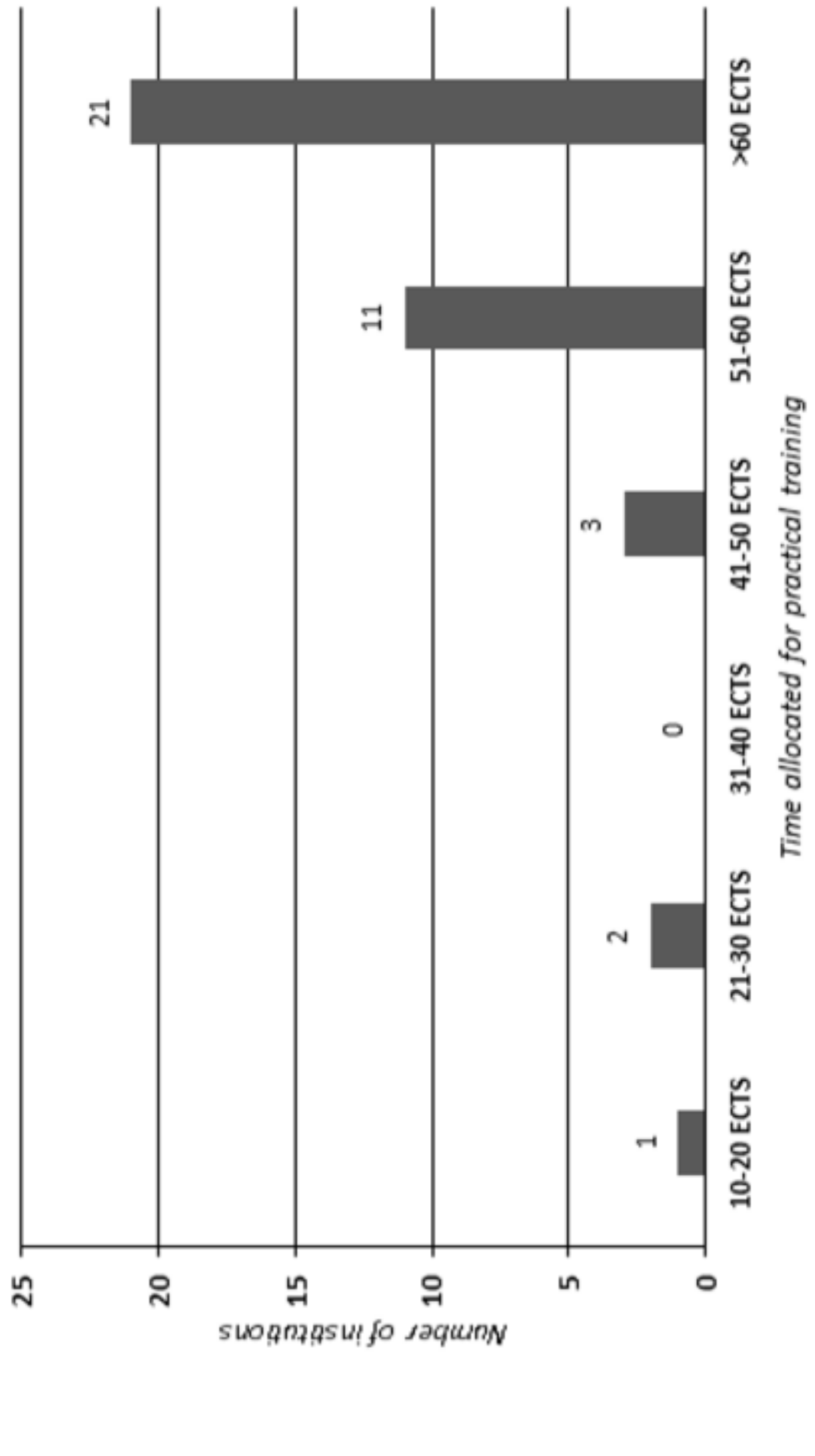




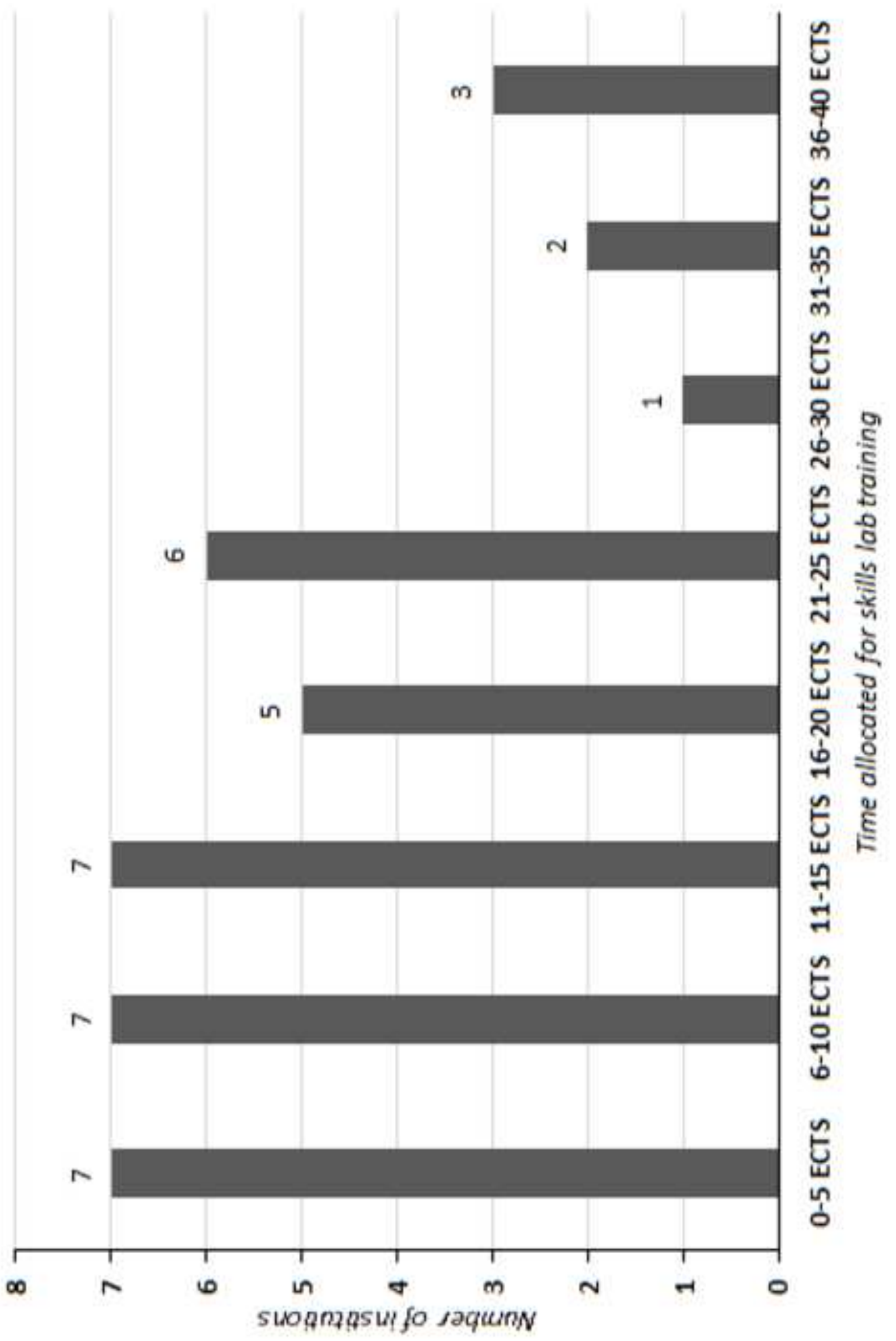

N

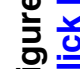



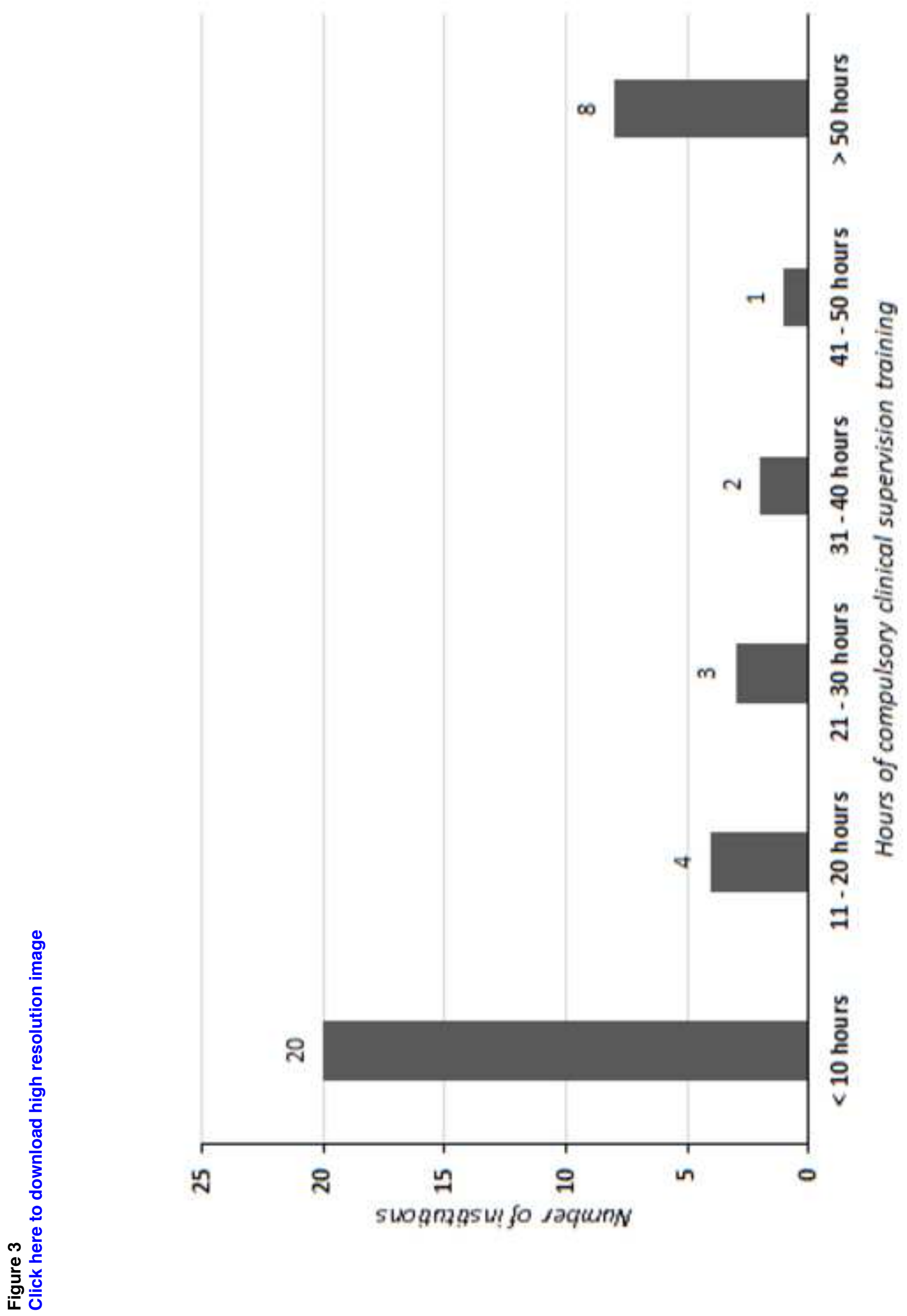


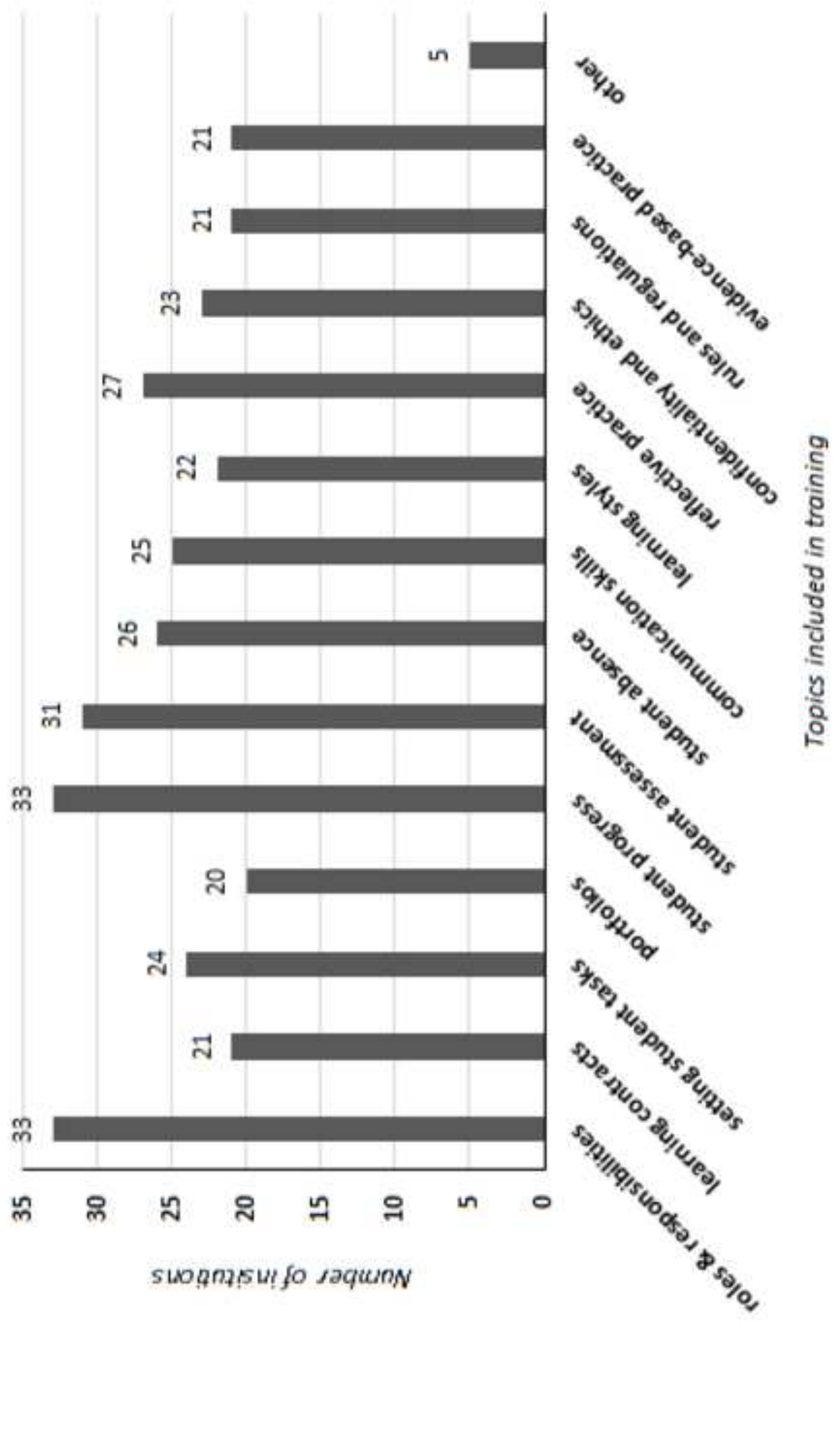




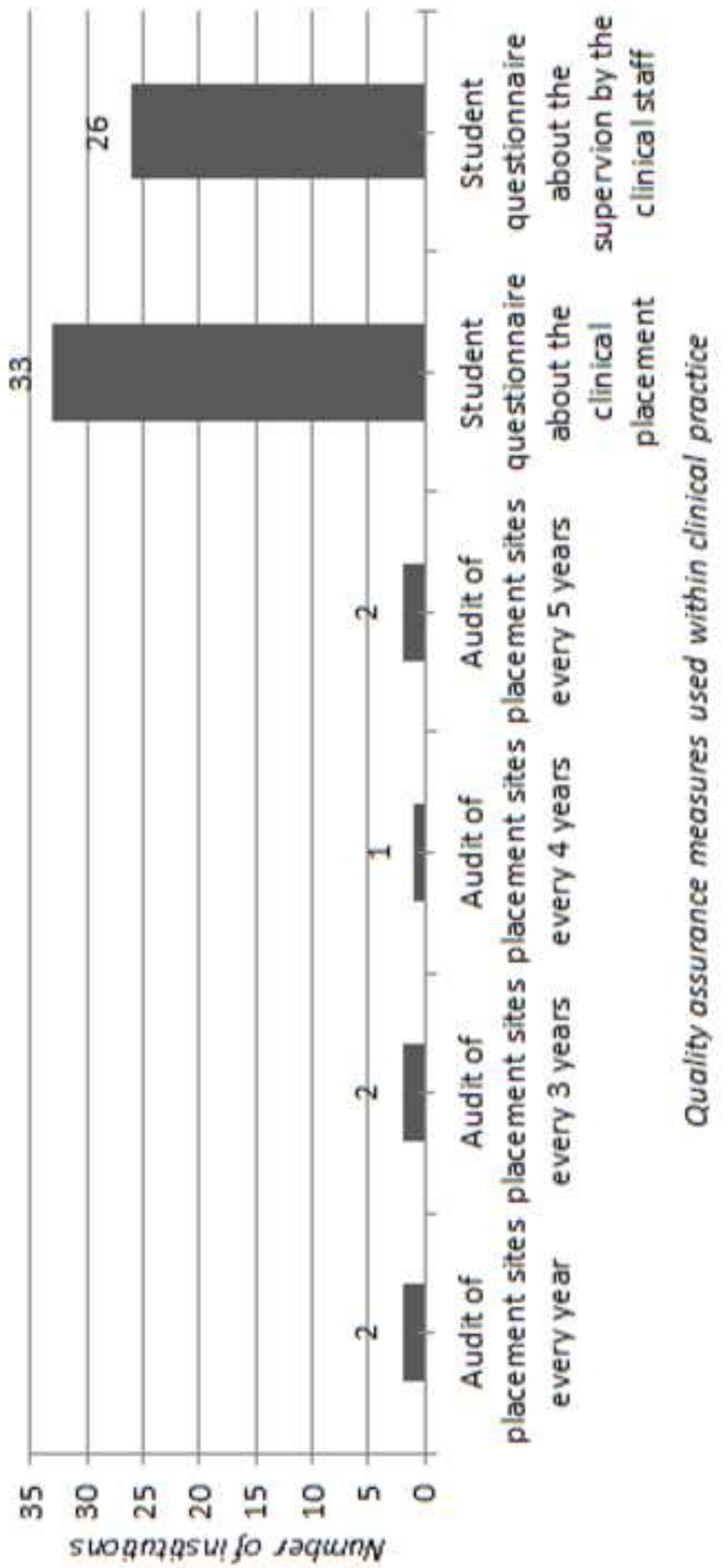




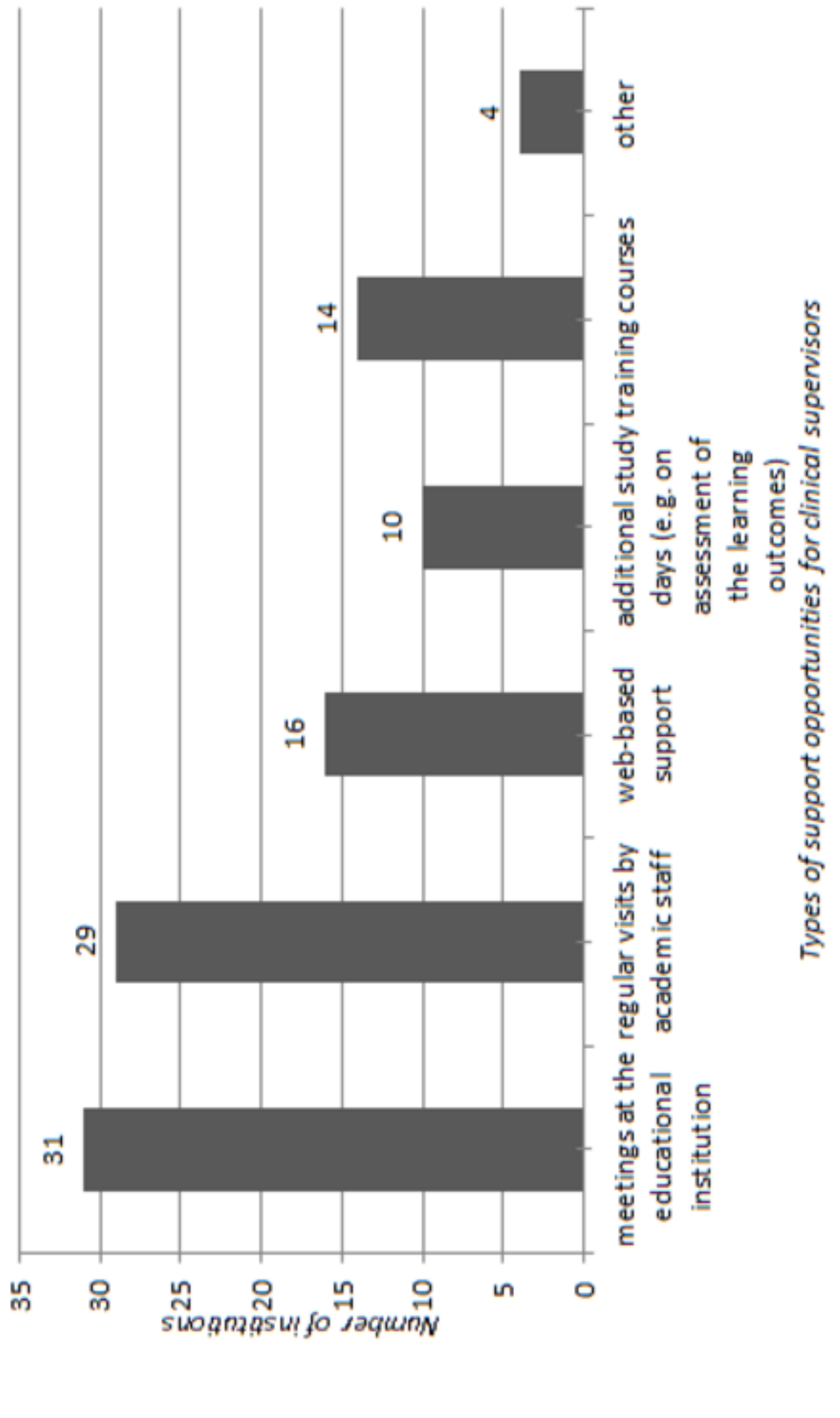




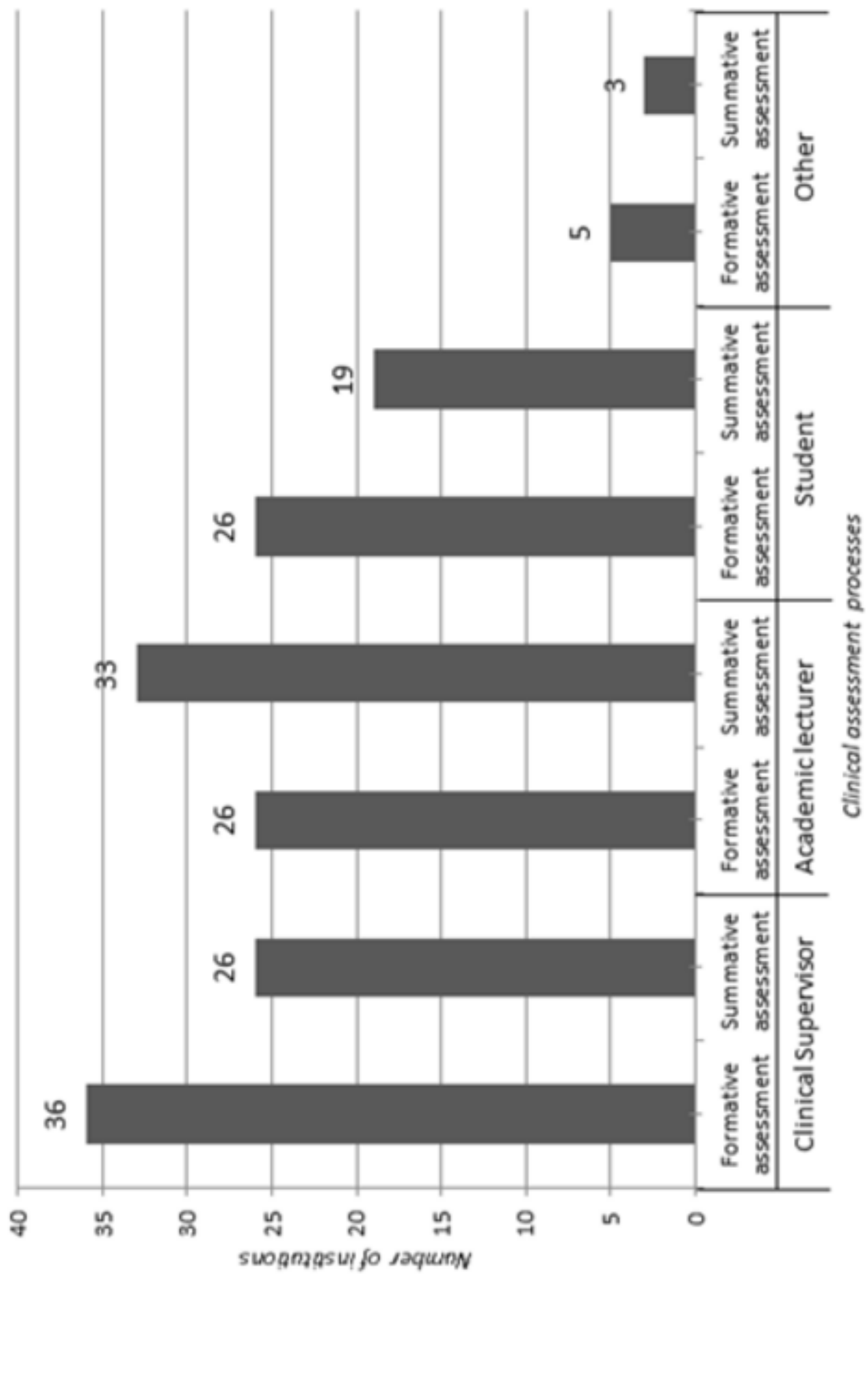


Figure 1. Total amount of programme time allocated for practical training

Figure 2. Total amount of programme time allocated for practical training in the skills lab

Figure 3. Hours of compulsory training required to be a clinical practice supervisor

Figure 4. A summary of topics included in training course for clinical practice supervisors

Figure 5. A summary of quality assurance measures utility in clinical practice

Figure 6. A summary of opportunities for support of the clinical supervisors

Figure 7. Who assesses the students formatively and summatively during clinical placement? 


\begin{tabular}{|c|c|c|c|c|c|}
\hline Country & Institution & Code & Country & Institution & Code \\
\hline Austria & FH Campus Wien & AT1 & Malta & University of Malta & MT1 \\
\hline Austria & FH Wiener Neustadt & AT2 & Netherlands & Fontys UoAS & NL1 \\
\hline Belgium & Institut Paul Lambin & BE1 & Netherlands & INHollland UoAS & NL2 \\
\hline Belgium & Odisee UoAS & BE2 & Netherlands & Hanze UoAS & NL3 \\
\hline $\begin{array}{l}\text { Czech } \\
\text { Republic }\end{array}$ & $\begin{array}{l}\text { University of West } \\
\text { Bohemia }\end{array}$ & $\mathrm{CZ1}$ & Norway & $\begin{array}{l}\text { Buskerud University } \\
\text { College }\end{array}$ & NO1 \\
\hline Denmark & $\begin{array}{l}\text { University College } \\
\text { Lillebelt }\end{array}$ & DK1 & Norway & $\begin{array}{l}\text { Gjøvik University } \\
\text { College }\end{array}$ & NO2 \\
\hline Estonia & $\begin{array}{l}\text { Tartu Health Care } \\
\text { College }\end{array}$ & EE1 & Norway & $\begin{array}{l}\text { Buskerud University } \\
\text { College }\end{array}$ & NO3 \\
\hline Finland & Oulu UoAS & FI1 & Norway & $\begin{array}{l}\text { Sør-Trøndelag } \\
\text { University College }\end{array}$ & NO4 \\
\hline Finland & Turku UoAS & $\mathrm{FI} 2$ & Portugal & $\begin{array}{l}\text { Escola Superior de } \\
\text { Tecnologia da Saúde } \\
\text { de Lisboa }\end{array}$ & PT1 \\
\hline Finland & $\begin{array}{l}\text { Helsinki Metropolia } \\
\text { UoAS }\end{array}$ & $\mathrm{FI3}$ & Portugal & $\begin{array}{l}\text { Escola Superior de } \\
\text { Tecnologia da Saude de } \\
\text { Coimbra }\end{array}$ & PT2 \\
\hline Finland & Novia UoAS & $\mathrm{Fl4}$ & Portugal & $\begin{array}{l}\text { CESPU Cooperativa de } \\
\text { Ensino Superior }\end{array}$ & PT3 \\
\hline France & IFNEM Nancy & FR1 & Slovenia & University of Ljubljana & SL1 \\
\hline Greece & $\begin{array}{l}\text { Technical University } \\
\text { of Athens }\end{array}$ & GR1 & Sweden & University of Lund & SE1 \\
\hline Hungary & $\begin{array}{l}\text { Semmelweis } \\
\text { University }\end{array}$ & HU1 & Sweden & Örebro University & SE2 \\
\hline Ireland & $\begin{array}{l}\text { University College } \\
\text { Dublin }\end{array}$ & IE1 & Sweden & $\begin{array}{l}\text { Jöngköping School of } \\
\text { Health Sciences }\end{array}$ & SE3 \\
\hline Italy & University of Bologna & IT1 & Switzerland & $\begin{array}{l}\text { UoAS Western } \\
\text { Switzerland }\end{array}$ & $\mathrm{CH} 1$ \\
\hline Italy & $\begin{array}{l}\text { Università "G. } \\
\text { dAnnunzio" Chieti }\end{array}$ & IT2 & United Kingdom & University of Ulster & GB1 \\
\hline Latvia & University of Latvia & LV1 & United Kingdom & University of Salford & GB2 \\
\hline Lithuania & Klaipeda University & LU1 & United Kingdom & $\begin{array}{l}\text { Robert Gordon } \\
\text { University }\end{array}$ & GB3 \\
\hline
\end{tabular}




\begin{tabular}{|c|c|c|c|}
\hline \multirow[t]{2}{*}{ Activities } & Regular basis & Sometimes & Not at al \\
\hline & \multicolumn{3}{|c|}{ n (\%) } \\
\hline Teach students & $18(47)$ & $18(47)$ & $\begin{array}{c}2(5) \\
\mathrm{BE} 2, \mathrm{CH} 1\end{array}$ \\
\hline $\begin{array}{l}\text { Monitor the student's progress in the } \\
\text { achievement of the learning outcomes }\end{array}$ & $33(87)$ & $\begin{array}{l}4(11) \\
\text { GB2, HU1, IT1, } \\
\text { NO2 }\end{array}$ & $\begin{array}{c}1(3) \\
\mathrm{CZ1}\end{array}$ \\
\hline Provides feedback to the student & $36(95)$ & $\begin{array}{c}1(3) \\
\text { IT2 }\end{array}$ & $\begin{array}{c}1(3) \\
\text { IT1 }\end{array}$ \\
\hline $\begin{array}{l}\text { Provides the feedback to the } \\
\text { educational institution about the } \\
\text { progress of clinical placement }\end{array}$ & $31(82)$ & $\begin{array}{l}7(18) \\
\text { DK1, EE1, FI1, } \\
\text { FR1, NL3, SL1, } \\
\text { NO2 }\end{array}$ & $0(0)$ \\
\hline $\begin{array}{l}\text { Assess the students achievement of } \\
\text { learning outcomes in clinical placement }\end{array}$ & $32(84)$ & $\begin{array}{c}5(13) \\
\text { CZ1, FR1, PT3, IT2, } \\
\text { NO2 }\end{array}$ & $\begin{array}{c}1(3) \\
\text { SE1 }\end{array}$ \\
\hline $\begin{array}{l}\text { Complete the paperwork related to the } \\
\text { student clinical training }\end{array}$ & $26(68)$ & $\begin{array}{c}10(26) \\
\text { SE2, F12, NL3, } \\
\text { NO3, NO4, PT3, } \\
\text { AT2, HU1, IT1, } \\
\text { NO2 }\end{array}$ & $\begin{array}{c}3(8) \\
\text { DK1, SE1, FI4 }\end{array}$ \\
\hline $\begin{array}{l}\text { Meet the management of the } \\
\text { department about the learning } \\
\text { environment }\end{array}$ & $\begin{array}{c}14(37) \\
\text { SE2, AT1, CZ1, DK1, } \\
\text { FI3, GB3, IE2, LU1, } \\
\text { NL1, NL2, NO1, PT1, } \\
\text { PT3, BE1, } \\
\end{array}$ & $22(58)$ & $\begin{array}{c}2(5) \\
\text { SE1, AT2 }\end{array}$ \\
\hline $\begin{array}{l}\text { Organise in house learning opportunities } \\
\text { for co-workers about student teaching }\end{array}$ & $\begin{array}{c}9(24) \\
\text { DK1, FI2, F13, GB2, } \\
\text { LU2, NL2, NO1, PT2, } \\
\text { PT3 }\end{array}$ & $21(55)$ & $\begin{array}{l}8(21) \\
\text { CZ1, EE1, FI1, } \\
\text { NL3, NO4, } \\
\text { AT2, FI4, GR1 }\end{array}$ \\
\hline $\begin{array}{l}\text { Participate in the time planning of the } \\
\text { clinical placement }\end{array}$ & $20(53)$ & $\begin{array}{c}12(32) \\
\text { BE2, AT1, CH1, } \\
\text { GB3, IE1, NL3, } \\
\text { NO1, NO4, SE3, } \\
\text { GR1, HU1, NO2 }\end{array}$ & $\begin{array}{c}6(16) \\
\text { FI1, FI2, FR1, } \\
\text { SE1, AT2, FI4 }\end{array}$ \\
\hline $\begin{array}{l}\text { Participate in the planning of the course } \\
\text { content }\end{array}$ & $\begin{array}{c}8(21) \\
\text { CZ1, FR1, GB1, LU1, } \\
\text { LV1, PT3, IT1, IT2 }\end{array}$ & $20(53)$ & $\begin{array}{c}10(26) \\
\text { BE2, SE2, FI1, } \\
\text { FI2, NL2, } \\
\text { NO1, NO3, } \\
\text { SE1, AT2, FI4 }\end{array}$ \\
\hline Assign the student to the departments & $17(45)$ & $\begin{array}{c}13 \text { (34) } \\
\text { SE2, AT1, FI3, FR1, } \\
\text { GB3, IE1, NL3, } \\
\text { PT2, SE3, SL1, } \\
\text { AT2, FI4, IT1 }\end{array}$ & $\begin{array}{l}8 \text { (21) } \\
\text { MT1, BE2, } \\
\text { EE1, FI1, NL2, } \\
\text { SE1, GR1, } \\
\text { HU1 }\end{array}$ \\
\hline
\end{tabular}


Meet the academic tutor to exchange information about the clinical placement

$13(34)$

MT1, AT1, CZ1,

DK1, EE1, FI1,

FR1, NL3, NO4,

$0(0)$

AT2, BE1, HU1, 